\title{
Impact Assessment of RAMed Medical Health Insurance on Access to Healthcare Using Instrumental Approach
}

\author{
Ouakil Hicham \\ Ability Professor, Faculty of Law, Economic and Social Sciences \\ Ibn Tofail University of Kenitra, Morocco \\ Lechheb Houda \\ Ability Professor, Faculty of Law, Economic and Social Sciences \\ Ibn Tofail University of Kenitra, Morocco
}

\author{
Jouilil Youness \\ Economic Researcher, Faculty of Law, Economic and Social Sciences \\ Ibn Tofail University of Kenitra, Morocco \\ E-mail: y.jouilil@gmail.com
}

Received: June 28, 2019

doi:10.5296/ber.v9i3.14987
Accepted: July 26, 2019 Published: August 9, 2019

URL: https://doi.org/10.5296/ber.v9i3.14987

\begin{abstract}
The generalization of the RAMed social project on 2012 is one of the key achievements that reflects the commitment of the Moroccan State to strengthen social cohesion and the fight against vulnerability. This article proposes to study the issue of the accessibility of RAMed's to Basic Health care in Morocco and in particular, to examine, empirically, the causal effect of the coverage by the RAMed health insurance on access to health care in public hospitals. In this respect and throughout this research paper, we will try to highlight the barriers limiting the accessibility of these and to appropriate health care structures, particularly those of a geographical, socio-economic, socio-demographic and cultural nature. The quantitative analysis conducted in this manuscript highlights a differential care recourse between people covered by basic medical coverage and those who are not covered by any type of medical
\end{abstract}


insurance. In detail, and taking into account social and economic variables, the use of care varies greatly and deeply depending on the coverage scheme. Indeed, members of RAMed (all types) and their descendants are those who consult medicine more than the uncovered. Thus, from the results obtained in this investigation, it is possible to identify two main lessons from which it is conceivable to sketch avenues for government action. Hence, thanks to the extension of RAMed sanitary coverage, the population has been able to access medical care, especially for the poorer classes. The promotion of health culture through awareness campaigns remain a great challenge for public action.

Keywords: Impact assessment, RAMed Moroccan Health Scheme, Instrumental variables

\section{Introduction}

RAMed is a Moroccan national free health care program. it allows the poor and the vulnerable the right of access to medical care through partial or total coverage depending on the economic situation of the beneficiaries.

The generalization of the RAMed Moroccan social project on 2012 is one of the key achievements that reflects the commitment of the Moroccan State to strengthen social cohesion and the fight against vulnerability and precariousness. Indeed, the entry of RAMed has increased the basic medical coverage of the Moroccan population especially for the most disadvantaged section of society. The analysis of the results of the Household Panel Survey Data reveals that the RAMed coverage system has increased the basic medical coverage rate from $23.4 \%$ in 2012 to $31.8 \%$ in 2013 and $45.6 \%$ in 2015. This improvement affected rural areas much more than urban areas, where coverage increased from $7.6 \%$ to $19.6 \%$ and then to $34.2 \%$ respectively. However, some questions remain for instance: Does this progression accompanied by the equitable access to health care between insureds by Basic Health Insurance and RAMedist people? Is the standard of living of households still a major determinant of access to care?

Specifically, this article proposes to study the question of the accessibility of RAMed's to Basic Health care in Morocco and in particular, to examine, empirically, the causal effect of the coverage by health care. RAMed health insurance on access to health care in public hospitals. In this respect and throughout this research paper, we will try to highlight the barriers limiting the accessibility of these to appropriate health care structures, particularly those of a geographical, socio-economic, socio-demographic and cultural nature. To achieve this, we will make use of the quantitative methods of impact evaluation of public policies, in particular the so-called instrumental variables method.

\section{Theoretical review}

At the microeconomic level, it is generally accepted that a low level of income in the face of relatively high medical expenses could lead to a debt in the formal institutions (banks, micro-credit associations, etc.) or even informal one (someone, Tontine, ... etc), the sale of assets and equipment owned by households especially by poor families. Thus, a short-term health shock can contribute to long-term impoverishment (Van Damme, W., LV Leemput, et al., 2004), (Annear, PL, Wilkinson, D., et al., 2007). In addition, households often cannot 
borrow easily, they can therefore give up valuable care and in the best cases, when they have access to care, they are often of poor quality, which may imply following the health problems.

In another point of view, the theory of health microeconomics states that health insurance coverage can solve this type of problem. Indeed, by taking care of the cost of health care, insurance can help to smooth consumption, reduce asset sales and new debts, and even increase the quantity and quality of care envisaged and consequently improve health outcomes. Hence, the main question that arises from this postulate. Will this hypothesis remain true when we speak about the Moroccan insurance of the poor? (Annear, P.L., D. Wilkinson, et al., 2007) and (Das, Hammer and Leonard, 2008). In other words, does RAMed Insurance encourage access to health care?

The first empirical studies on the impact of insurance coverage on access to health care date back to the 20th century with the work of (Arrow, 1963) and (Andersen RM, Newman JF, 1973). These and all subsequent research have shown that the causal relationship between the two factors indicated is a cause-and-effect relationship and that health insurance positively influences the use of health services. Indeed, the partial or total coverage of health care costs allow policyholders to have access to a large number of health treatments, especially the most expensive, which explains in a large part the direct path and positive of this relationship. (Caussat Laurent, Raynaud Denis, 2004). Does this corollary remain valid for the case of Moroccan medical insurance for indigents?

Therefore, this research paper proposes to carry out an analysis of the causal effect of the possession of RAMed health insurance on the use of health care. To do this, this contribution uses a new source of data on the levels and living conditions of Moroccan households, namely cross-sectional data from household microeconomic surveys, with a view to clarifying the links between RAMed medical coverage. on the use of health care?

\section{Tools and Methodology}

\subsection{Data Sources}

The study population consists of ordinary (cross-sectional) households that make up the sample of the Household Panel Survey for the 2015's wave.

It is also important to note that morbidity and health care utilization issues refer to the reference period of four weeks prior to the surveyor's visit date to the sample household.

\subsection{Coverage of Moroccan Population}

According to the 2015 NAHI official publications, the number of RAMed beneficiaries (actually registered) has significantly changed in recent years to reach 9,133,488 people, of which almost $88 \%$ are vulnerable. With regard to Compulsory Health Insurance (CHI), the number of beneficiaries is estimated at about 8.736 million, of which $65.51 \%$ comes mainly from the private sector. (National Agency of Health Insurance, 2015)

In total, the number of people covered by the Basic Medical Coverage (BMC) for the year of 


\section{Macrothink}

2016 hardly exceeds 17.4 million beneficiaries or just over half of the Moroccan population.

At the national level, the RAMed medical insurance coverage rate is of the order of $21.4 \%$ (compared to only $10.1 \%$ in 2012), which is almost a little over one fifth of the total Moroccan population. However, some regions remain far from this average. This is the case of the Draa-Tafilalt regions, the 3 southern regions, Beni-Mellal Khénifra and Souss-Massa. Once again, this observation remains valid, true and unchangeable for both areas of residence.

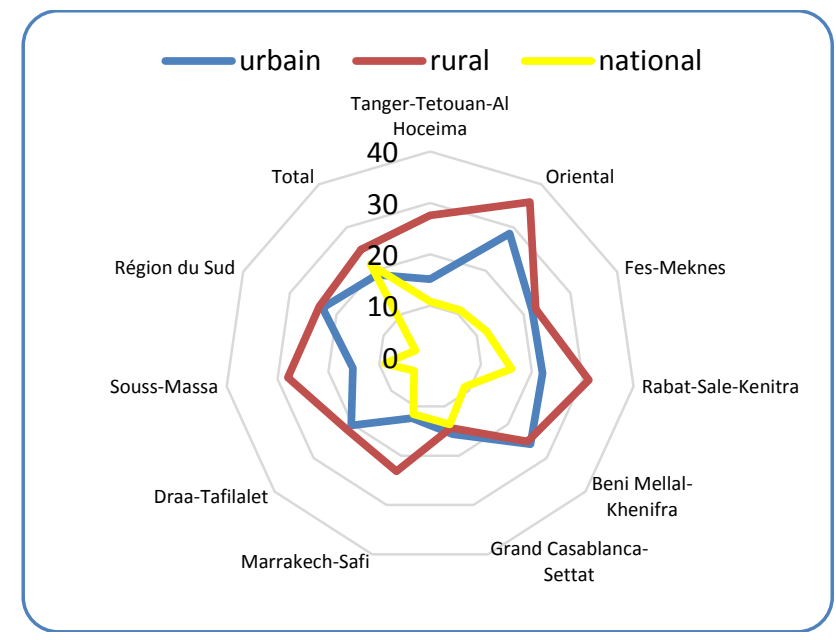

Figure 1. Coverage of the Moroccan population by RAMed by region and area of residence (Source: Authors calculations)

\subsection{Hypotheses}

Based on the literature review of demand and health care consumption especially (Grossman M., 1972), (Anderson, G, and Peter H., 2000) and (Jouilil Y., Lechheb H. \& Ouakil H., 2018), the basic assumption of this research paper is that coverage by a medical coverage system -RAMed in our case- would stimulate the demand for care health. In other words, the main hypothesis of this investigation will be as follows:

$H_{0}: R A M e d$ Medical Insurance, like any other type of health insurance, would have a positive impact on the use of care.

\section{Methodology}

Since the early 2000s, Morocco has intensified its efforts to ensure that all its population has widespread and equitable access to health care services. These objectives are in line with the Sustainable Development Goals (SDGs) to which Morocco is committed.

Thus, we will try to econometrically test the following hypothesis: Has the new regime introduced really allowed the population of beneficiaries to access health care? To do this, we will opt for the following standard linear regression model:

$$
\left\{\begin{array}{c}
Y_{j}=X_{j} \beta+\xi D_{j}+\varepsilon_{j} ; \forall \mathrm{j}=1, \ldots, \mathrm{N} \\
D_{j}=W_{j} a+\delta_{j} ; \forall \mathrm{j}=1, \ldots, \mathrm{N}
\end{array}\right.
$$




\section{Macrothink}

Business and Economic Research

ISSN 2162-4860

2019, Vol. 9, No. 3

Such as:

- X Explanatory variables of the first model that are supposed to be exogenous;

- $\varepsilon$ et $\delta$ refer to the terms of system errors;

- D Explanatory variable of treatment that is supposed endogenous (RAMed in our case);

- W Bloc of instrumental variables;

- $\mathrm{Y}$ is the opportunity to go to see a care specialist in case of illness. It's a dichotomous variable:

$$
Y_{j}=\left\{\begin{array}{ccc}
1 & \text { if } j \text { use healthcare } ; \\
& 0 & \text { otherwise }
\end{array}\right.
$$

The unknown parameter coefficient $\xi$ measures the estimate of the causal effect of the treatment. This means that this parameter captures the impact of RAMed medical insurance coverage on access to care.

In another wake and to be able to estimate the parameters of this type of model, one can opt for the technique of the instrumental variables through the double least squares method since it provides reliable and unbiased estimators. (Angrist J. \& Jörn-Stephen P., 2009).

\subsection{Econometric Modelling}

In this second section, we will focus on transitions by type of coverage between consultation and non-consultation of a health care specialist (doctor, nurse, ...). Specifically, we will examine the causal effect of RAMed coverage of all types on access to health care. We would also like to take advantage of the cross-sectional dimension of the household panel survey and try to draw a profile of people who are more likely to be in health care.

\subsubsection{Presentation of the Used Variables}

To modulate the impact of RAMed medical coverage on access to health care, we will use the block of explanatory variables listed below:

a) Explained Variable

Consult: is a variable to explain, binary which is 1 if the individual interviewed consults a health care specialist (general practitioner, medical specialist, nurse, ... etc.) Regardless of the type of consultation carried out curative and / or preventive in the reference period of the survey and 0 otherwise.

b) Explanatory variables

Several factors have been used to explain the behaviour of individuals regarding the use of health care, including socioeconomic, socio-demographic and cultural characteristics, namely:

RAMed: is a dichotomous variable, which takes the value 1 if the individual is insured by 
RAMed and 0 in the opposite case.

Complementary Health Insurance (CHI): refers to the possession of complementary insurance. It is equal to 1 if the person surveyed has supplementary insurance (all types combined) and 0 otherwise.

Age: Age is one of the demographic factors most likely to influence an individual's decision about the use of health care services. Thus, it will be used as a quantitative regressor.

Gender: Among the demographic variables that influence the consumption of care, we find the gender of the individual (male / female). It will be integrated into the model as a binary qualitative variable.

Marital status (Marital_stat): The marital status of the individual is among the variables influencing the use of health care. For this purpose, the value 0 is assigned for singles, 1 for married-e-s and 2 for divorced-and-widows.

Area of residence (residence): The residential environment (urban / rural) is one of the explanatory variables for the use of health care providers.

Household size (Hh_size): Household size is one of the demographic factors that can influence people's behavior regarding health care use. It will be used as a discrete quantitative variable.

Number of years of study (Nbr_year_stud): Education and in particular the number of years of study is one variable that may explain the use of health care.

Gender of the household head (Gender_HH): The object of integration of this variable in the model is to test the behaviours of households headed by a woman on the health decision of its members. Thus, the value 1 is assigned for households headed by women and 0 where applicable.

The standard of living of households approached by the average annual per capita expenditure (AAPE) is among the key factors that explain the demand in terms of quantity and quality of health care.

It is important to point out at this level that this list is not exhaustive, other explanatory variables can also be used to approximate the impact of the variable of interest.

\subsection{Descriptive Statistics}

In this section, we present the results of a descriptive and analytical analysis of access to health care according to certain economic and social characteristics.

\subsection{Reporting Morbidity and Health Care Use}

The results of the 2015 household panel survey shown that about $11.37 \%$ of those surveyed reported having at least one morbidity episode during the reference period of the survey (the month before the survey). Of these, $61.90 \%$ reported using a professional to seek care during the same reference period. 


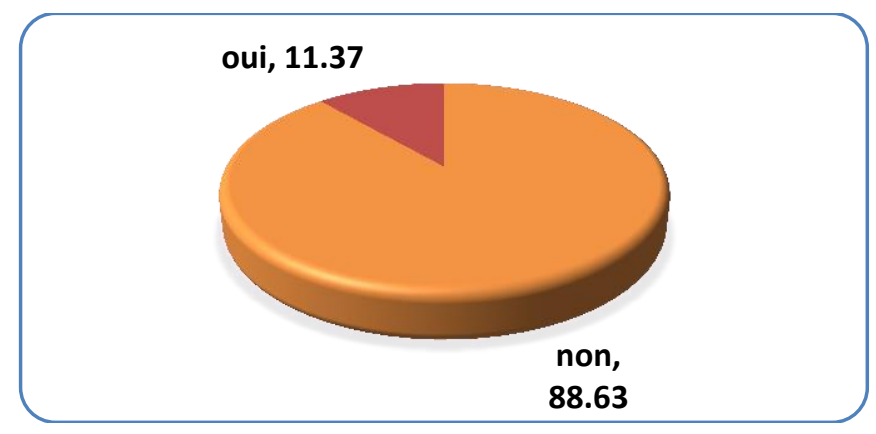

Figure 2. Morbidity rate (\%) (Source: Authors calculations)

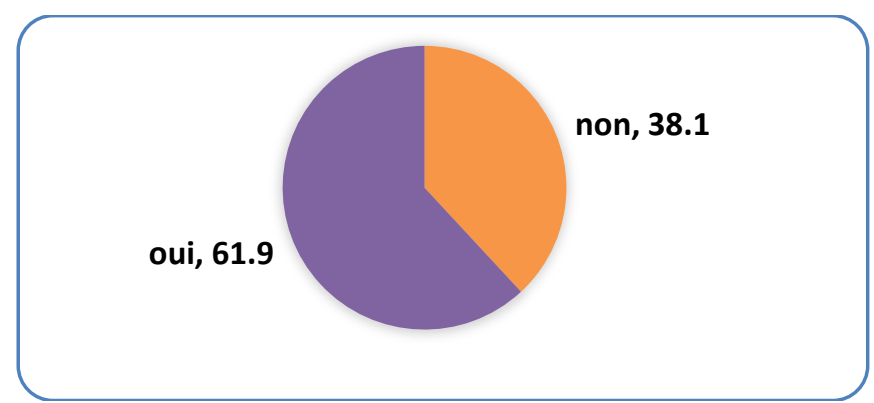

Figure 3. Rate of consultation by persons who declared themselves sick during the reference period of the survey (Source: Authors calculations)

\subsubsection{Qualitative Variables}

Depending on the standard of living, it can be seen that the consultation rate is distributed unevenly according to the quintiles of expenditure. Thus, it rises gradually with the improvement of living conditions. Indeed, it is at its lowest level for the 1st quintile (the poorest) or it hardly exceeds the threshold of $39 \%$ while it is close to $71 \%$ for the 5 th quintile (the wealthiest). This agrees that the disparities are more pronounced according to standard of living and that access to care (for the sick) remains highly dependent on their socio-economic conditions.

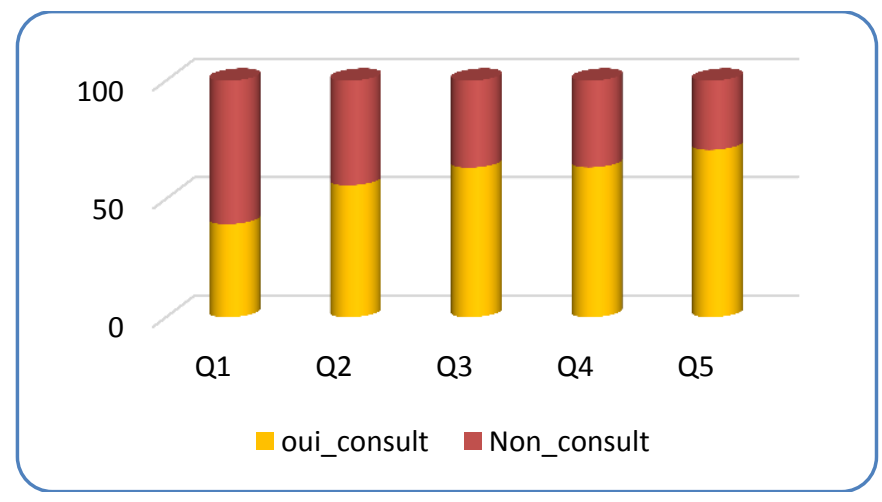

Figure 4. Consultation rate by standard of living (Source: Authors calculations)

Insured persons and members of a health insurance plan consult more than the uninsured in case of illness. In fact, the consultation rate increases from $58 \%$ for non-insured persons to $70.78 \%$ for insured persons by CHI (all types combined) and from $61.14 \%$ to $63.87 \%$ for covered by RAMed. This proves that access to a medical coverage scheme favours the use of 
care staff.

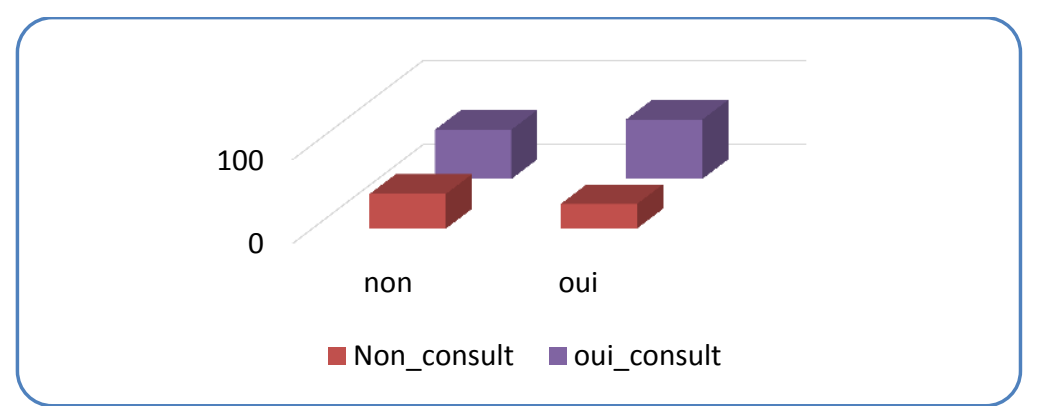

Figure 5. Rate of consultation for CHI members (Source: Authors calculations)

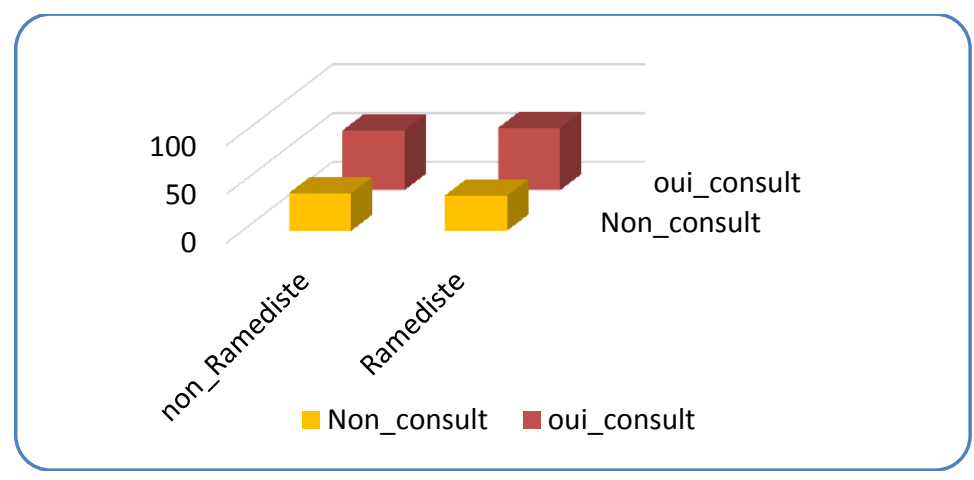

Figure 6. Rate of consultation for RAMed members (Source: Authors calculations)

Same for supplementary health insurance. In fact, the consultation rate goes from $61.83 \%$ for those who are not covered by complementary medical insurance to almost $74 \%$ for those who have it.

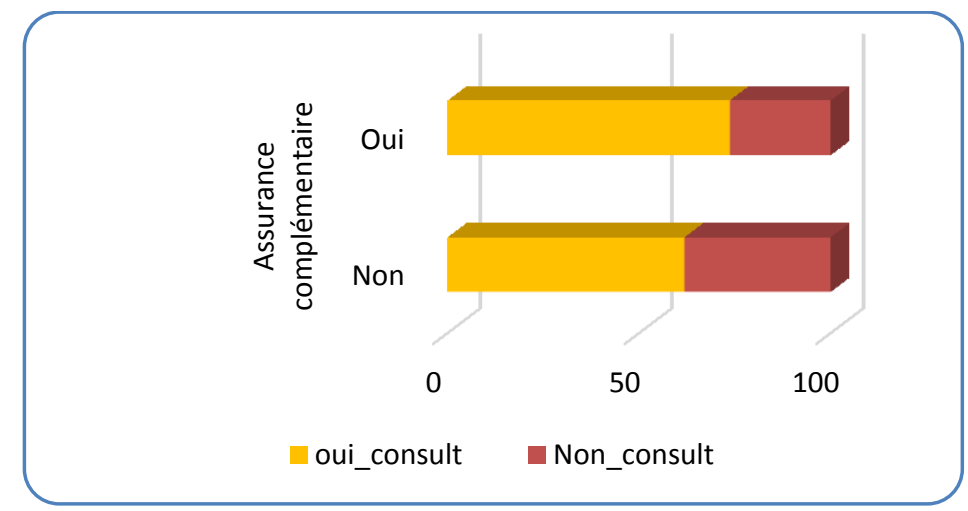

Figure 7. Consultation rate for members of supplementary insurance (Source: Authors calculations)

The graph below illustrates the behaviour by individual type with respect to the health system. A significant difference exists between the two sexes. Indeed, the rate of consultation of women is almost twice that of men. This asserts the assumption that women are more likely to consult and place more importance on their health status than their counterparts.

A slight difference is found between individuals in terms of marital status (figure below). Being married-or- widowed increases the chances of going to see a doctor in case of sickness 


\section{Macrothink}

Business and Economic Research

ISSN 2162-4860

2019, Vol. 9, No. 3

compared to being single. In fact, it goes from $63.67 \%$ for married $(62.07 \%$ divorced and widowed) to almost $58.36 \%$ for single people.

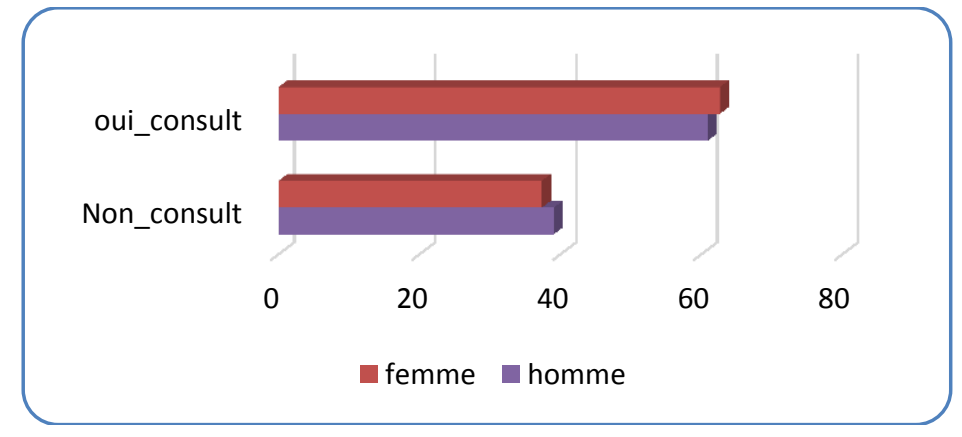

Figure 8. Genre consultation rate (Source: Authors calculations)

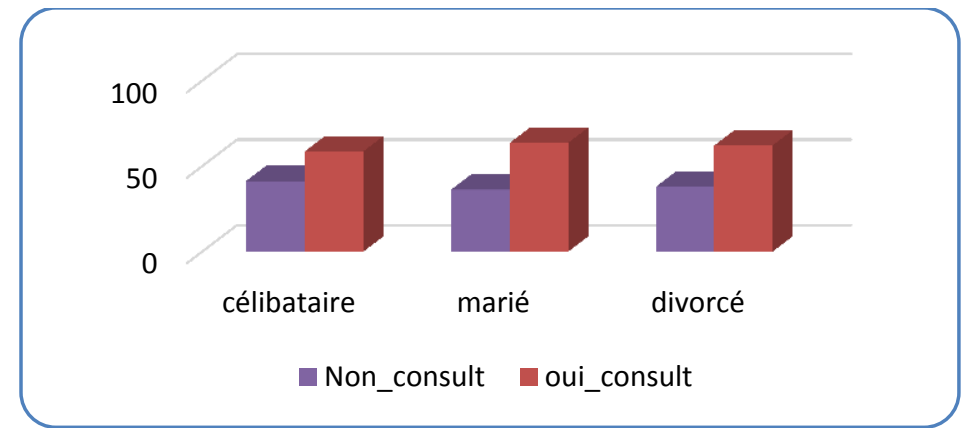

Figure 9. Rate of consultation by marital status (Source: Authors calculations)

There is some difference between the two areas of residence in relation to consultation status. Indeed, in the urban environment, the consultation rate of care specialists exceeds (13\%) and while in rural areas, it hardly exceeds the franchise of (10\%). Thus, we find that the urban declares more morbidity and consult more compared to the rural ones. (a) Is this difference due to the fact that rural people are less sick than urban dwellers or (b) because when they are sick, they do not seek care (due to other latent and unmeasurable characteristics).

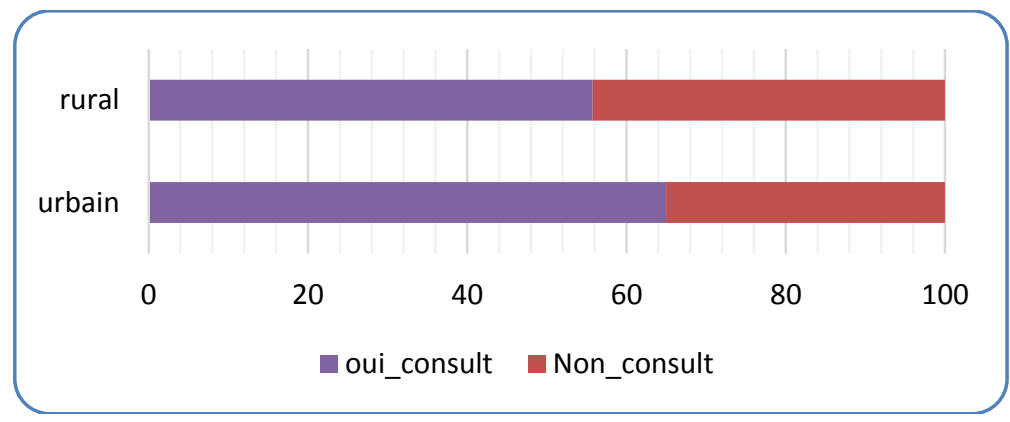

Figure 10. Rate of consultation by zone of residence (Source: Authors calculations)

\subsubsection{Quantitative Variables}

Compared to the reference period (four weeks of implementation of the survey), the average age of those who took out a consultation was 44.81 (versus 43.08 for those who did not consult).

In addition, it can be seen from Table 4 that while the household size increases while the 


\section{Macrothink}

Business and Economic Research

ISSN 2162-4860

2019, Vol. 9, No. 3

consultation rate is decreased. In fact, it goes from 5.133 people per dwelling for people who have made a consultation to 5.015 people per dwelling for those who did not use it.

There is a notable difference in the health behavior of individuals by number of years of study. It's 3.88 years for those who consult while it does not exceed the threshold of 2.96 years for those who do not consult.

Table 1. Consultation by age

\begin{tabular}{|c|c|c|c|c|c|}
\hline \multirow{2}{*}{ Age } & Consult & Mean & std.Err & \multicolumn{2}{|c|}{ [95\% Conf. Interval] } \\
\cline { 2 - 6 } & No & 43.08 & 0.563 & 41.974 & 44.186 \\
\cline { 2 - 6 } & Yes & 44.81 & 0.4533 & 43.922 & 45.97 \\
\hline
\end{tabular}

Source: Authors calculations

Table 2. Consultation by household size

\begin{tabular}{|c|c|c|c|c|c|}
\hline & Consult & Mean & std.Err & \multicolumn{2}{|c|}{ [95\% Conf. Interval] } \\
\hline \multirow{2}{*}{ Hh_size } & No & 5.133 & 0.056 & 5.022 & 5.245 \\
\cline { 2 - 6 } & Yes & 5.015 & 0.043 & 4.929 & 5.101 \\
\hline
\end{tabular}

Source: Authors calculations

Table 3. Rate of consultation by number of years of study

\begin{tabular}{|c|c|c|c|c|c|}
\hline & Consult & Mean & std.Err & \multicolumn{2}{|c|}{ [95\% Conf. Interval] } \\
\hline \multirow{2}{*}{ Nbr_year_stud } & No & 2.965 & 0.109 & 2.751 & 3.179 \\
\cline { 2 - 6 } & Yes & 3.880 & 0.097 & 3.688 & 4.072 \\
\hline
\end{tabular}

Source: Authors calculations

\subsection{Estimation, Validation and Interpretation}

The organization of this section will be subdivided into four stages. First, we will discuss the estimation of the parameters of the chosen model. Secondly, we will present an interpretation of the results found. Thirdly, we will state the main conclusions drawn from this investigation and finally, we will issue the major recommendations.

1. Estimation of the econometric model

The table below gives the results, in terms of marginal effects, of the econometric model adopted (the probability of going to consult a care specialist according to the socio-demographic and socio-economic characteristics of individuals and their households of origin.) estimated by two methods namely the Ordinary Least Square Method (OLS) and the Instrumental Variables (IV) Method. 


\section{Macrothink}

Business and Economic Research

ISSN 2162-4860

2019, Vol. 9, No. 3

Table 4. Estimation of the Econometric Model Adopted Using the Instrumental Variables Method and the Ordinary Least Square Method

\begin{tabular}{|c|c|c|c|}
\hline CONSULT & Modalities & IV & OLS \\
\hline \multirow[t]{3}{*}{ RAMed } & \multirow[t]{2}{*}{ Yes } & $0.163 * *$ & $0.092 * * *$ \\
\hline & & $(0.0765)$ & $(0.022)$ \\
\hline & $\mathrm{No}$ & REF & REF \\
\hline \multirow[t]{3}{*}{ CHI } & \multirow[t]{2}{*}{ Yes } & $0.155 * *$ & $0.089 * * *$ \\
\hline & & $(0.0611)$ & $(0.023)$ \\
\hline & No & REF & REF \\
\hline \multirow[t]{3}{*}{ Residence } & \multirow[t]{2}{*}{ Rural } & $-0.1087 *$ & 0.000429 \\
\hline & & $(0.0683)$ & $(0.021)$ \\
\hline & Urban & REF & REF \\
\hline \multirow[t]{5}{*}{ Age } & \multirow[t]{2}{*}{ Child } & 0.0913 & 0.0283 \\
\hline & & $(0.0910)$ & $(0.034)$ \\
\hline & Adult & REF & REF \\
\hline & \multirow[t]{2}{*}{ Old } & 0.0622 & 0.0226 \\
\hline & & $(0.0599)$ & $(0.0215)$ \\
\hline \multirow[t]{3}{*}{ Gender } & \multirow[t]{2}{*}{ Female } & $0.0479 * *$ & $0.0164 *$ \\
\hline & & $(0.0526)$ & $(0.0193)$ \\
\hline & Male & REF & REF \\
\hline \multirow[t]{5}{*}{ Marital_stat } & Single & REF & REF \\
\hline & \multirow[t]{2}{*}{ Married } & $0.143 *$ & 0.0444 \\
\hline & & $(0.0768)$ & $(0.0288)$ \\
\hline & \multirow[t]{2}{*}{ Widow or Divorced } & 0.0342 & 0.0069 \\
\hline & & $(0.0993)$ & $(0.03677)$ \\
\hline \multirow[t]{9}{*}{ AAPE } & $1^{\text {st }}$ quintile & REF & REF \\
\hline & \multirow[t]{2}{*}{$2^{\text {nd }}$ quintile } & $0.433 * * *$ & $0.167 * * *$ \\
\hline & & $(0.0945)$ & $(0.036)$ \\
\hline & \multirow[t]{2}{*}{$3^{\text {rd }}$ quintile } & $0.616^{* * *}$ & $0.242 * * *$ \\
\hline & & $(0.0913)$ & $(0.0341)$ \\
\hline & \multirow[t]{2}{*}{$4^{\text {th }}$ quintile } & $0.626 * * *$ & $0.248 * * *$ \\
\hline & & $(0.0904)$ & $(0.0337)$ \\
\hline & \multirow[t]{2}{*}{$5^{\text {th }}$ quintile } & $0.812 * * *$ & $0.319 * * *$ \\
\hline & & $(0.0935)$ & $(0.0342)$ \\
\hline \multirow{2}{*}{\multicolumn{2}{|c|}{ Hh_size }} & 0.0334 & 0.013 \\
\hline & & $(0.0113)$ & $(0.00414)$ \\
\hline \multirow{2}{*}{\multicolumn{2}{|c|}{ Nbr_year_stud }} & $0.0108^{*}$ & $0.00345^{*}$ \\
\hline & & $(0.00585)$ & $(0.00206)$ \\
\hline \multirow[t]{3}{*}{ Gender_HH } & \multirow[t]{2}{*}{ Yes } & 0.105 & $0.0333 * *$ \\
\hline & & $(0.0706)$ & $(0.0258)$ \\
\hline & No & REF & REF \\
\hline \multirow{2}{*}{\multicolumn{2}{|c|}{ Constant }} & $-0.696 * * *$ & $0.206 * * *$ \\
\hline & & $(0.131)$ & $(0.0489)$ \\
\hline Observations & & 4,233 & 4,233 \\
\hline LR chi2(15) & & 138.98 & ---- \\
\hline $\mathrm{F}(15,4209)$ & & ------- & 11.41 \\
\hline Prob > chi 2 & & 0.0000 & 0.0000 \\
\hline Pseudo R2 & & 0.0354 & 0.0517 \\
\hline
\end{tabular}

Source: Authors calculations

Note: Parentheses indicate robust standard errors.

$* \mathrm{p}<0,1, * * \mathrm{p}<0,05 ; * * * \mathrm{p}<0,001$.

The estimates shown in the table are the IV and OLS estimators. 
It should be noted that the estimates found were obtained using R software.

Based on the results of the regression shown in the table above, it seems that the model estimated using the instrumental variable technique provides a better estimate of the unknown parameters of the model, because it takes into account the endogeneity of the RAMed variable and provide unbiased estimators with minimal variances. This leads us to opt for the technique of instrumental variables instead of the standard method of regression.

\subsection{Interpretation}

The estimation of the econometric model adopted, using the instrumental variables method, shows that RAMed medical insurance coverage has a positive and statistically significant impact $(+16.3 \%)$ on the use of care $(\mathrm{p}<0.001)$. This proves that the implementation of the RAMed medical scheme allows, and even encourages, individuals, particularly beneficiaries, to make more use, in case of illness, to health care professionals. In this respect, it can be said that thanks to the generalization of RAMed health coverage, the population has been able to access certain treatments that were previously inaccessible because of their prohibitive costs (kidney failure, hepatitis, cardiovascular diseases, etc.), for the poor and relatively poor classes.

In sum, coverage by all types of health insurance has a statistically significant effect on the likelihood of accessing health care. In fact, the results of the estimates assert that compared to uninsured, those covered by basic $\mathrm{CHI}(+15.5 \%)$ more chance of seeking care. $(\mathrm{P}<0.05)$

In addition to the influences of basic medical coverage, the impact of socio-economic, socio-demographic and cultural characteristics is confirmed here, highlighting a significant difference between people from families with literate and women living in urban areas, and persons from large families whose members of households are illiterate and reside in rural areas.

Residence in rural areas has a negative and statistically different effect of zero on the use of care. Indeed, for all things equal, rural people have less than $10.87 \%$ chance to consult compared to city dwellers. This is mainly due to the lack of access to health facilities.

By age group, we find that children and the elderly attend health facilities more than adults. This is explained by the fact that these two categories of people are those who are very fragile and most likely to be affected by a disease. However, this result is statistically insignificant at the critical threshold of $5 \%$.

With regard to the marital status of the individual, it has a considerable effect on the use of care. In this respect, being married - or widowed - increases the probability of using care specialists compared to being single, by 14.3 and 3.42 percentage points, respectively.

For household size and contrary to expectations, it is associated positively and statistically insignificant with the use of health care. ( $p>0.05)$. This leads us to reject the hypothesis that individuals living in more populous households are at greater risk of not consulting a health specialist. 
Also, the gender of the individual has a significant and statistically different effect of zero at the critical threshold of $5 \%$ on the consultation. Indeed, women are more likely $(+4.79 \%)$ to seek treatment compared to men.

In addition, households headed by women are more likely to go to a health care specialist. Specifically, being head of household and female increases the relative probability of using health care by 10.5 percentage points.

At the same time, the econometric study carried out has highlighted the importance of other socio-economic and cultural factors (standard of living, level of education, etc.) on whether to give up health care or not.

The probability of consulting increases gradually with the increase in the level of education of the individual (number of years of study). Thus, studying one more year multiplies by $1.08 \%$ the probability of going to see a care specialist. In other words, having a high level of education increases the likelihood of seeking care. Thus, people with a high level of education are more likely to use modern medicine. This shows the scale and the essential role that education training plays in determining the health behaviour of individuals.

However, and despite all the State efforts made for the generalization of equitable and equal access for all Moroccan citizens to health care, the standard of living of households is still a major determinant of health, craze for care. Indeed, it can be seen from the parameters of the estimated model that the more people's standard of living improves, the greater the likelihood of going in search of disease. Thus, it goes from $43.3 \%$ for the second quintile to more than $81.2 \%$ for the fifth quintile (the wealthiest). This is consistent with assumptions that individuals with high standards of living value and value their health and the health of their descendants.

\section{Conclusions}

The quantitative analysis conducted in this article highlights a differential care recourse between people covered by basic medical coverage and those not covered by any type of medical insurance. In detail, and taking into account social and economic variables, the use of care varies greatly depending on the coverage scheme. Indeed, members of RAMed (all types) and their descendants are those who consult medicine more than the uncovered.

Thanks to the generalization of sanitary coverage RAMed, the population has been able to access to care especially for the poorer classes. From the foregoing, one wonders, does this scheme actually reduce the care costs borne by households, especially by household heads?

\section{References}

Andersen, R. M., \& Newman, J. F. (1973). Societal and individual determinants of medical care utilization in the United States. Milbank Memorial Fund Quarterly-Health and Society, 51(1), 95-124. https://doi.org/10.2307/3349613

Anderson, G., \& Peter, H. (2000). Population Aging: A Comparaison among Industrialized Contries. Health Affairs, 19(3), 191-203. https://doi.org/10.1377/hlthaff.19.3.191 
Angrist, J., \& Jörn-Stephen, P. (2009). Instrumental Variables in Action: Sometimes You Get What You Need. Mostly Harmless Econometrics, MIT Press.

https://doi.org/10.1515/9781400829828-009

Annear, P. L., Wilkinson, D. et al. (2007). Study of Financial Access to Health Services for the Poor in Cambodia. Phnom Penh, Cambodia Ministry of Health, WHO, AugAID, RMIT University.

Asada, Y., \& Kephart, G. (2007). Equity in health services use and intensity of use in Canada. Biomed Central Health Services Research, 7(41), 1-12.

https://doi.org/10.1186/1472-6963-7-41

Brown, J. R., \& Finkelstein, A. (2009). The Private Market for Long-Term Care Insurance in the United States: A Review of the Evidence. Journal of Risk and Insurance, 76(1), 5-29. https://doi.org/10.1111/j.1539-6975.2009.01286.x

Grossman, M. (1972). On the concept of health capital and the demand for health. Journal of Political Economy, 80, 223-225. https://doi.org/10.1086/259880

Jouilil, Y., Lechheb, H., \& Ouakil, H. (2018). Dépenses et utilisation de soins de santé: Une revue de littérature théorique et empirique. European Scientific Journal November 2018 edition, 14. https://doi.org/10.19044/esj.2018.v14n33p156

Jouilil, Y., \& Lechheb, H. (2018). Effect of Moroccan Health Insurance on Individuals' Healthcare Utilization and Expenditures: A Hicket Model. Journal of Private Equity. Winter, 22(1) 87-90. https://jpe.iijournals.com/content/22/1/87

Kroeger, A. (1983). Anthropological and socio-medical health care research in developing countries. Social Science and Medicine, 17(3), 147-161.

https://doi.org/10.1016/0277-9536(83)90248-4

Lechheb, H., Ouakil, H., \& Jouilil, Y., (2018). Evaluation des Politiques Publiques: Outil Efficace au Service du Développement. Revue du Contrôle de la Comptabilité et de l'Audit. Numéro 6: Septembre 2018.

https://journals.indexcopernicus.com/api/file/viewByFileId/417519.pdf

Objectifs du Développement Durable, cible 3.8. (2017). Le Guide sur les droits de l'homme dans les Objectifs de Développement Durable Relier les droits de l'homme avec tous les objectifs de développement durable.

Ouakil, H., Lechheb, H., \& Jouilil, Y. (2018). Évaluation d'impact: Revue de littérature. IOSR Journal of Business and Management (IOSR-JBM). pp. 13-17.

http://www.iosrjournals.org/iosr-jbm/papers/Vol20-issue11/Version-1/C2011011317.pdf

Van Damme, W., Van Leemput, L., Por, I., Hardeman, W., \& Meessen, B. (2004). Out-of-pocket Health Expenditure and Debt in Poor Households: Evidence from Cambodia. Tropical Medicine and International Health, 9(2), 273-280.

https://doi.org/10.1046/j.1365-3156.2003.01194.x 


\section{Copyright Disclaimer}

Copyright for this article is retained by the authors, with first publication rights granted to the journal.

This is an open-access article distributed under the terms and conditions of the Creative Commons Attribution license (http://creativecommons.org/licenses/by/3.0/). 